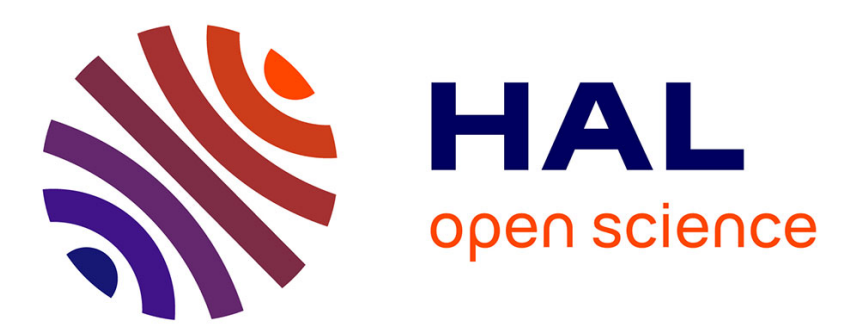

\title{
Bond Graph model of a vertical U-tube steam condenser coupled with a heat exchanger.
}

\author{
Kamal Medjaher, A.K. Samantaray, B. Ould-Bouamama
}

\section{To cite this version:}

Kamal Medjaher, A.K. Samantaray, B. Ould-Bouamama. Bond Graph model of a vertical U-tube steam condenser coupled with a heat exchanger.. International Journal of Simulation Modelling Practices and Theory, 2009, 17 (1), pp.228-239. 10.1016/j.simpat.2007.10.002 . hal-00192556

\section{HAL Id: hal-00192556 https://hal.science/hal-00192556}

Submitted on 28 Nov 2007

HAL is a multi-disciplinary open access archive for the deposit and dissemination of scientific research documents, whether they are published or not. The documents may come from teaching and research institutions in France or abroad, or from public or private research centers.
L'archive ouverte pluridisciplinaire HAL, est destinée au dépôt et à la diffusion de documents scientifiques de niveau recherche, publiés ou non, émanant des établissements d'enseignement et de recherche français ou étrangers, des laboratoires publics ou privés. 


\title{
Bond Graph Model of a Vertical U-Tube Steam Condenser Coupled with a Heat Exchanger
}

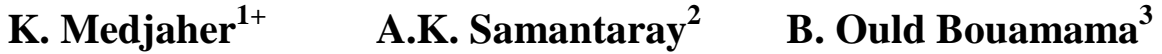 \\ ${ }^{1}$ LAB, CNRS UMR 6596, ENSMM de Besançon, 26 Chemin de l'Epitaphe, 25030 Besançon, France \\ ${ }^{2}$ Department of Mechanical Engineering, Indian Institute of Technology, 721302 Kharagpur, India \\ ${ }^{3}$ LAGIS, CNRS UMR 8146, Université de Lille-1, 59655 Villeneuve d'Ascq Cedex, France
}

\begin{abstract}
A simulation model for a vertical U-tube steam condenser in which the condensate is stored at the bottom well is developed in this paper. The U-tubes carrying the coolant are partially submerged in the stored condensate and thus the bottom well acts as a heat exchanger. The storage of hydraulic and thermal energies is represented using a coupled pseudo-bond graph model. Advection effects are modelled by considering reticulated segments of the tubes carrying coolant, over which condensation takes place. The developed model is of intermediate complexity and it is intended for use in observer based real time process supervision, which works by comparing the process behaviour to the reference model outputs. The simulation results obtained from the bond graph model are validated with experimental data from a laboratory set-up.
\end{abstract}

Keywords: Vertical steam condenser; Heat exchanger; Bond graph

\section{Introduction}

Modern process engineering plants are designed to reuse the material and energy for improving the process efficiency and also to reduce production costs. The process dynamics of such systems is usually complex and consequently designing them for optimal utilisation of resources requires a well-developed simulation model. However, each component's model must not be too complex because the component's model is not only used for simulation of the single process component's behaviour, but also used to predict the overall steady state and dynamic response of the process. Furthermore, process models are being increasingly used for online monitoring, diagnosis of process faults, and fault tolerant control; and this requires real time computations of the model output for comparison with the actual process behaviour. Therefore, one needs faster numerical computation using a simplified, but accurate process model.

In this paper, model of a vertical U-tube steam condenser coupled with a heat exchanger is developed and the model complexity is limited to the intermediate level.

Steam condensers are integral part of any nuclear and thermal power plant utilising steam turbines, distillation industries using water as a solvent, etc. System-level modeling of steam condensers has to consider both mass and energy balances in two control volumes, namely steam and condensate, and energy balance in further two control volumes, namely tubes and the coolant flowing through them. That is why bond graph modelling as a multi-energy

\footnotetext{
${ }^{+}$Corresponding author

Tel: +330381402795

Email: Kamal.medjaher@ens2m.fr
} 
domain approach is a suitable tool for representing such systems [1-5]. Furthermore, the conservative nature of junction structure in a bond graph model ensures that the material and energy balances are correctly represented in each step.

The literature on bond graph modeling of heat exchangers is pervasive [6-10]. They are based on pseudo-bond graph representations of thermo-fluid transport and heat exchange developed in [11-14]. Thoma [2, 10] has even introduced the term 'HEXA', as a generic nomenclature, for the bond graph sub-model of a heat exchanger.

On the other hand, very few works on bond graph modeling of condensers are reported in literature. Some of the works on bond graph modeling of condensation phenomena assume bulk condensation (similar to cloud formation and its saturation) and base the analysis on the relative humidity [15-16] in the control volume. Other bond graph formulations for storage and transport of two-phase mixtures (water and steam mixture, here) may be consulted in [1718]. Bond graph representations of film condensation on vertical tubes were developed in [10, 19-20]. However, the film condensation models developed therein are inaccurate because they assume the entire segments of the tube to be at uniform temperature. In this paper, we consider the temperature variation in the tube by considering several small and finite segments. This approach for bond graph modeling of distributed-parameter multiphase thermodynamic systems has been developed in [17] by using convection bonds. Further note that a pseudo-bond graph model of a U-tube steam generator (boiler) has been developed in [21] by using one-dimensional finite-element modeling concept, which is similar to the one followed in this paper.

\section{Modelling}

Steam condensation involves both convection and conduction [22-23]. In process engineering systems, it is simpler to use enthalpy flow instead of entropy flow to model heat convection using pseudo-bond graph representation [10-14]. In this paper, pressure and temperature are considered as the generalised effort variables, and mass flow rate and enthalpy flow rate are taken as the generalised flow variables. The convection heat transfer due to mass flow is represented using inter-domain couplings presented in [20]. Note that a simpler model for this type of condenser has been developed in [20] for fault detection.

\subsection{Description of the condenser}

The schematic diagram of the coupled U-tube condenser and heat exchanger system is given in Fig.1. The steam enters from the top and is condensed over the outer surface of vertical tubes carrying low temperature liquid coolant. There are a number of U-tubes of equal length; only one of them is shown in Fig. 1.

The condensate film thickness grows as it flows down because of further condensation of steam on film's surface. The condensate is stored at the bottom of the condenser. The stored condensate is referred to as a pool and its level is controlled, i.e. kept within a range about a set point, by using an on-off controller acting on the discharge valve. Parts of the U-tubes carrying the coolant are submerged in the pool and there is further heat transfer from stored condensate in the pool to the cooling tubes. The rate of condensation of steam can be controlled by adjusting the pool level set point, which adjusts the tube surface area exposed to the steam. Such flexibility in controlling the rate of condensation, which consequently controls the steam flow rate, makes this type of condensers suitable for use in variable load installations. 


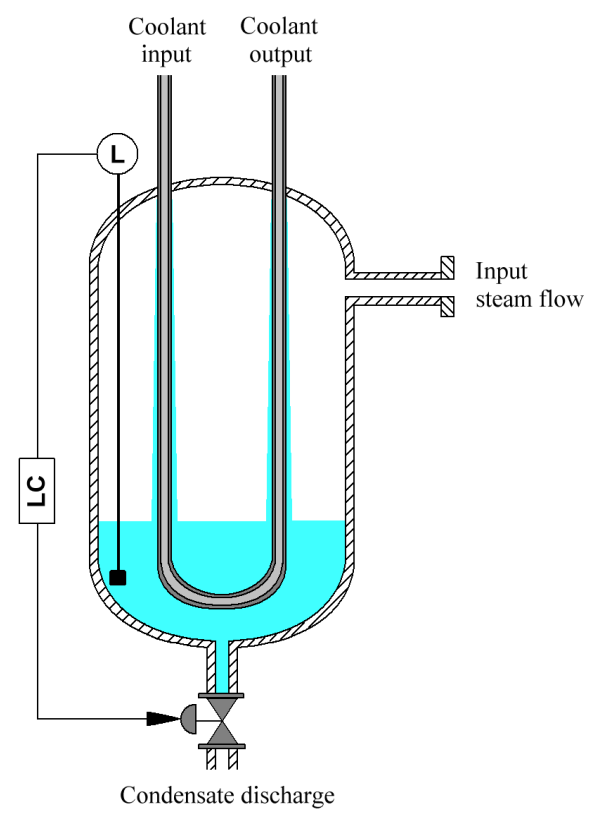

Fig.1. The coupled condenser-heat exchanger system

\subsection{Modelling assumptions}

To develop an intermediate complexity model, the following assumptions are made:

1. Non-condensable gases degrade the efficiency of condensers operating in subatmospheric vacuum pressure. Therefore, non-condensable gases are regularly vented out, usually from the boiler. We assume that the input steam is saturated and pure.

2. Usual Nusselt's assumptions [22, 24-25] are made:

a. The steam temperature is assumed to be homogenous in the vapour phase.

b. The wall temperature in each finite-reticule used in the model is uniform.

c. The condensate flow is laminar.

d. The maximum film thickness is small when compared to the tube's diameter.

3. The liquid phase is assumed to be incompressible.

4. It is assumed that the condenser is well insulated and heat loss to environment is negligible.

5. The condensation/evaporation over/from the pool surface is neglected.

\subsection{Problem formulation}

The variables, used in the analysis and model, are given in Table 1 . The values for geometric parameters correspond to an experimental set-up, which is discussed later in this paper.

We assume that the bent of the U-tubes is always submerged in the pool. The two sections of a U-tube above the pool are each divided in to $i$ number of finite elements which are enumerated starting from the coolant entry point (see Fig. 2). The submerged part of a U-tube is considered as a single finite element. Therefore, the total number of finite elements used to model a tube is $2 i+1$. 
Table 1. Model variables

\begin{tabular}{|c|c|c|c|}
\hline Variable & Description & Value & Unit \\
\hline$V_{c}$ & $\begin{array}{l}\text { Internal volume of the condenser excluding the volume } \\
\text { occupied by U-tubes }\end{array}$ & $9 \times 10^{-3}$ & $\mathrm{~m}^{3}$ \\
\hline$A_{c}$ & $\begin{array}{l}\text { Cross-sectional area of the condenser excluding the are } \\
\text { occupied by U-tubes }\end{array}$ & $1.277 \times 10^{-2}$ & $\mathrm{~m}^{2}$ \\
\hline$n_{t}$ & Number of U-tubes & 10 & - \\
\hline$l_{t}$ & Total length of each U-tube inside condenser & 1.6 & $\mathrm{~m}$ \\
\hline$l$ & Total length of each U-tube in contact with steam & - & $\mathrm{m}$ \\
\hline$l_{s}$ & Length of each reticulated segment & - & $\mathrm{m}$ \\
\hline$L$ & Pool level & - & $\mathrm{m}$ \\
\hline$L_{\min }$ & Minimum level setpoint of on-off controller & 3.5 & litres \\
\hline$L_{\max }$ & Maximum level setpoint of on-off controller & 4.5 & litres \\
\hline$D$ & Outer diameter of U-tube & 0.007 & $\mathrm{~m}$ \\
\hline$d$ & Inner diameter of U-tube & 0.003 & $\mathrm{~m}$ \\
\hline$\mu$ & Dynamic viscosity of condensate & $3.05 \times 10^{-4}$ & $\mathrm{~kg} \mathrm{~m}^{-1} \mathrm{~s}^{-1}$ \\
\hline$\lambda$ & Thermal conductivity of condensate & 0.675 & $\mathrm{~J} \mathrm{~m}^{-1} \mathrm{~s}^{-1} \mathrm{~K}^{-1}$ \\
\hline$L_{v}$ & Latent heat of vaporisation (function of pressure) & - & $\mathrm{J} \mathrm{kg}^{-1}$ \\
\hline$X$ & Steam quality & - & - \\
\hline$C_{d}$ & Valve's overall coefficient of discharge & $9 \times 10^{-5}$ & $\mathrm{~kg} \mathrm{~s}^{-1} \mathrm{~Pa}^{-1 / 2}$ \\
\hline$g$ & Gravity & 9.81 & $\mathrm{~m} \mathrm{~s}^{-2}$ \\
\hline$\rho$ & Density of water (condensate and coolant) & 1000 & $\mathrm{~kg} \mathrm{~m}^{-3}$ \\
\hline$c_{p}$ & Specific heat of water & 4184 & $\mathrm{~J} \mathrm{~kg}^{-1} \mathrm{~K}^{-1}$ \\
\hline$c_{p m}$ & Specific heat of tube's metal & 419 & $\mathrm{~J} \mathrm{~kg}^{-1} \mathrm{~K}^{-1}$ \\
\hline$\rho_{m}$ & Density of tube's metal & 7850 & $\mathrm{~kg} \mathrm{~m}^{-3}$ \\
\hline$\lambda_{m}$ & Thermal conductivity of tubes metal & 46.73 & $\mathrm{~J} \mathrm{~m}^{-1} \mathrm{~s}^{-1} \mathrm{~K}^{-1}$ \\
\hline$\dot{m}_{s}, \dot{H}_{s}$ & Mass and enthalpy flow rates of steam & - & $\mathrm{Kg} \mathrm{s}^{-1}, \mathrm{~J} \mathrm{~s}^{-1}$ \\
\hline$\dot{m}_{c}, \dot{H}_{c}$ & Mass and enthalpy flow rates of condensate & - & $\mathrm{kg} \mathrm{s}^{-1}, \mathrm{~J} \mathrm{~s}^{-1}$ \\
\hline$\dot{m}_{l}, \dot{H}_{l}$ & Mass and enthalpy flow rates from pool & - & $\mathrm{kg} \mathrm{s}^{-1}, \mathrm{~J} \mathrm{~s}^{-1}$ \\
\hline$\dot{m}_{\text {cool }}$ & Mass flow rate of coolant through U-tubes & 0.694 & $\mathrm{~kg} \mathrm{~s}^{-1}$ \\
\hline$\dot{H}_{\text {cool }}$ & Enthalpy flow rate of coolant through U-tubes & - & $\mathrm{J} \mathrm{s}^{-1}$ \\
\hline$\rho_{v}$ & Density of steam as a function of steam pressure & - & $\mathrm{kg} \mathrm{m}^{-3}$ \\
\hline$T_{s}$ & Steam temperature & - & $\mathrm{K}$ \\
\hline$P_{s}$ & Steam pressure & - & $\mathrm{Pa}$ \\
\hline
\end{tabular}

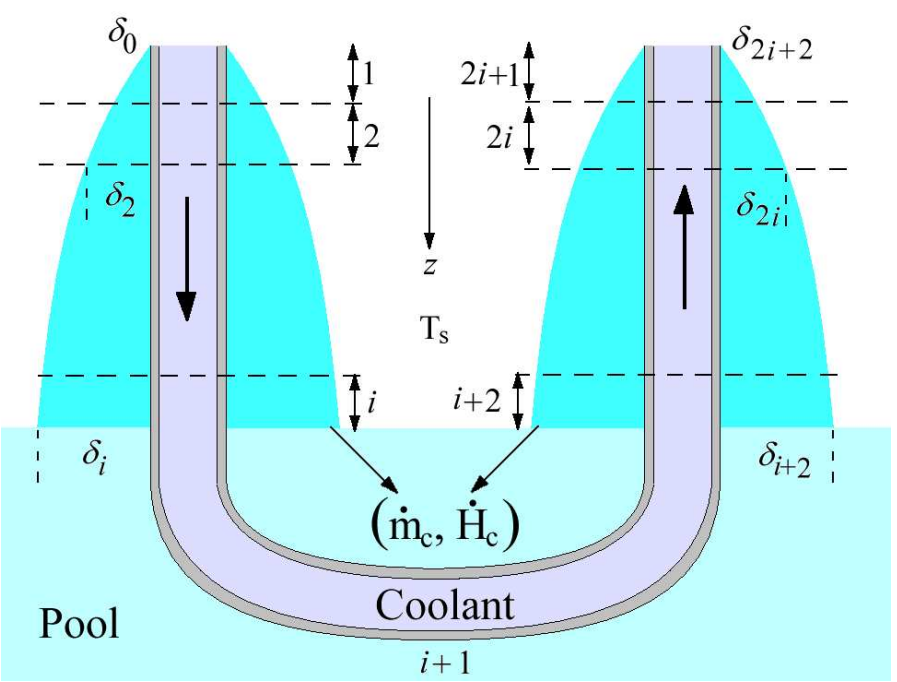

(a)

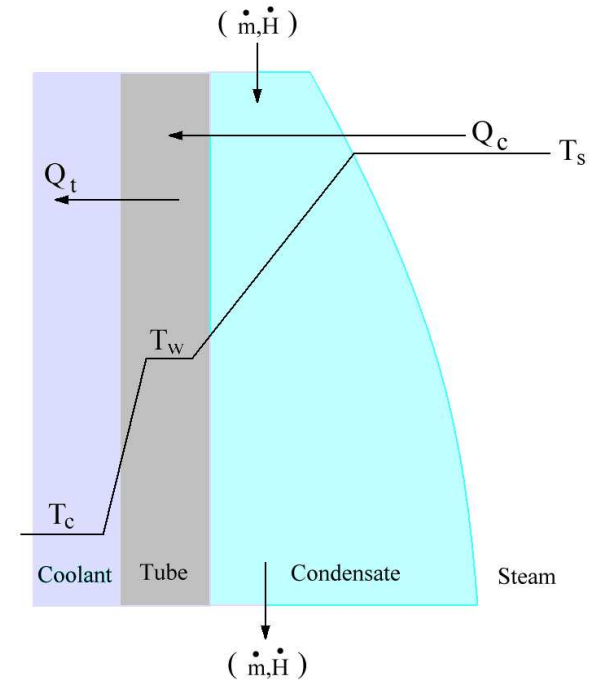

(b)

Fig. 2. (a) Exaggerated view of sections of the tube and (b) representation of temperature profile in one section (not to scale) 
Condensation occurs in elements 1 to $i$ and also in elements $i+2$ to $2 i+1$. The heat, withdrawn from the steam due to condensation and also due to further sub-cooling of the flowing condensate from each section, is directly transferred to the metallic body of that section of the U-tube. This heat is then transferred from the metallic body to the flowing coolant. The condensate fluid film thickness grows as it flows downwards to the pool, i.e. in paths $1 \rightarrow 2 \rightarrow \ldots i$ and $2 i+1 \rightarrow 2 i \rightarrow \ldots i+2$. The fresh condensate enters the pool in sections $i$ and $i+2$.

We apply Nusselt's condensation formulae [22] in each segment of the tube. In each section, the initial fluid film thickness is determined from the maximum fluid film thickness obtained from the segment which is geometrically just above the concerned section. The differential equation for film thickness [23-24], $\delta$, as a function of coordinate $z$ (see Fig. 2) is given as

$$
\delta^{3} \frac{d \delta}{d z}=\frac{\lambda \mu}{L_{v}^{\prime} \rho\left(\rho-\rho_{v}\right) g}\left(T_{s}-T_{w j}\right),
$$

where $T_{w j}$ is the tube wall temperature in $j^{\text {th }}$ section and $L_{v}^{\prime}=X L_{v}+0.68 c_{p}\left(T_{s}-T_{w j}\right)$. In the top most sections, i.e. sections 1 and $2 i+1$, the initial conditions are $\delta(0)=\delta(2 i+2)=0$. We use reticulated segments of tubes and then the film thickness, $\delta_{j}$, at the bottom of $j^{\text {th }}$ section is given by

$$
\delta_{j}=\left(\delta_{0}^{4}+\frac{4 \lambda \mu\left(T_{s}-T_{w j}\right)}{L_{v}^{\prime} \rho\left(\rho-\rho_{v}\right) g} l_{s}\right)^{\frac{1}{4}}
$$

where

$$
\delta_{0}=\left\{\begin{array}{l}
\delta_{j-1} \text { for } j \in[1, i], \\
\delta_{j+1} \text { for } j \in[i+2,2 i+1] .
\end{array}\right.
$$

The length of each segment of tube in contact with steam is calculated dynamically from

$$
l=l_{t}-\Phi_{c}(L) \text {, and } l_{s}=\frac{l}{2 i},
$$

where $\Phi_{c}$ is a complex non-linear function, which determines the length of the U-tubes submerged in the pool. Note that due to the bent of the U-tube and also non-linear geometry at the bottom of the condenser, it is very difficult to obtain a symbolic equation for this function and usually it is evaluated using interpolations from a calibrated table of experimental data for a specific condenser.

The mass flow rate of condensate into the pool is calculated at the sections in contact with the pool, i.e. in $i^{\text {th }}$ and $(i+2)^{\text {th }}$ section. Consequently, the total condensate flow is given by

$$
\dot{m}_{c}=n_{t} \pi D \frac{\rho g\left(\rho-\rho_{v}\right)}{3 \mu}\left(\delta_{i}^{3}+\delta_{i+2}^{3}\right) .
$$

The heat transferred from the steam phase to the tube's wall in each section, $j$, per unit mass is given by $L_{v}^{\prime}=X L_{v}+0.68 c_{p}\left(T_{s}-T_{w j}\right)$ in which the amount of heat withdrawn for condensation is $L_{v}$ and the rest is due to sub-cooling of the condensate. The actual sub-cooling is about 10 to $20 \%$ higher than the theoretically calculated value [24]. Thus the amount of heat, $Q_{c j}$, conducted to the tubes in each section, $j$, is given by

$$
Q_{c j}=n_{t} \pi D \frac{\rho g\left(\rho-\rho_{v}\right)}{3 \mu} \delta_{j}^{3}\left(X L_{v}+\alpha .0 .68 c_{p}\left(T_{s}-T_{w j}\right)\right),
$$

where $\alpha$ is a correction factor (between 1.0 to 1.2). Without sub-cooling, the condensate temperature would be the saturated liquid temperature, i.e. $T_{s}$. Thus the amount of heat stored in unit mass of condensate is given by 


$$
c_{p} T_{s}-0.68 \alpha c_{p}\left(T_{s}-T_{w j}\right) .
$$

Then the total enthalpy flow into the pool from sections $i$ and $i+2$ is given by

$$
\dot{H}_{c}=n_{t} \pi D c_{p} \frac{\rho g\left(\rho-\rho_{v}\right)}{3 \mu}\left(\delta_{i}^{3}\left(T_{s}-0.68 \alpha\left(T_{s}-T_{w i}\right)\right)+\delta_{i+2}^{3}\left(\left(T_{s}-0.68 \alpha\left(T_{s}-T_{w(i+2)}\right)\right)\right)\right),
$$

where $T_{w i}$ and $T_{w(i+2)}$ are respectively the tube wall temperatures in sections $i$ and $i+2$.

These formulations are used in the following sections to construct the bond graph model of the condenser. Note that the formulations described in this section are simple and more accurate formulations are available in literature (see [25-26] for extended Nusselt's formulation, [27] for Maxwell-Stefan equation based formulations for mixtures, [28] for effect of non-condensable gases, [29-30] for effect of wavy interface, etc., and the references therein for further details).

\subsection{Bond graph model of condenser}

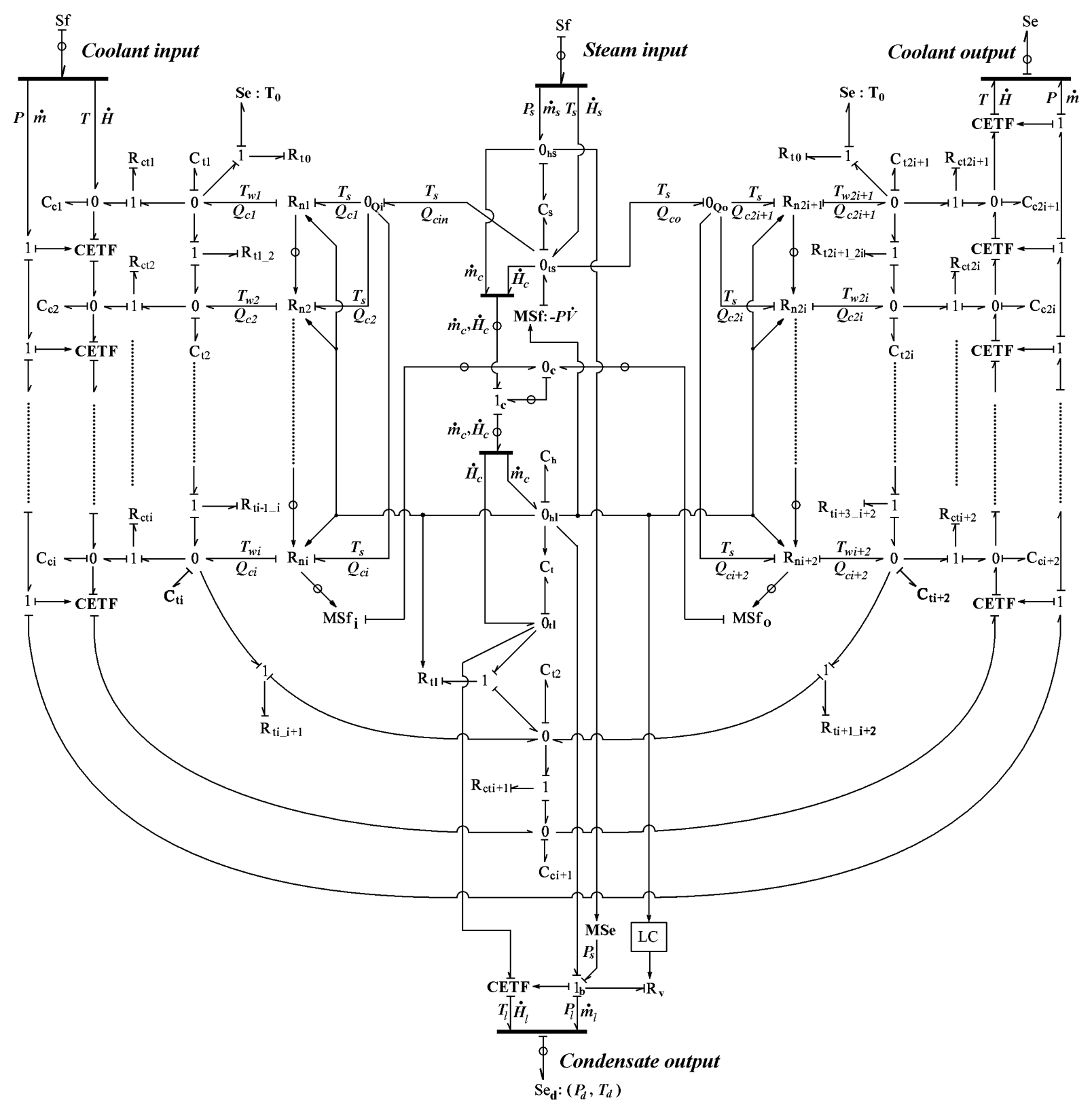

Fig. 3. Pseudo-bond graph model of the condenser-heat exchanger system 
The pseudo-bond graph model of the vertical condenser-heat exchanger system is given in Fig.3. The bonds and signals with a circle over them are vectors [10]. Thick perpendicular lines are used to decompose vector bonds and signals to their scalar forms and vice versa.

The thermo-fluid coupling is represented using CETF (coupling element for thermo-fluid) [20] in Fig.3. The structure of this element is defined in Fig.4.
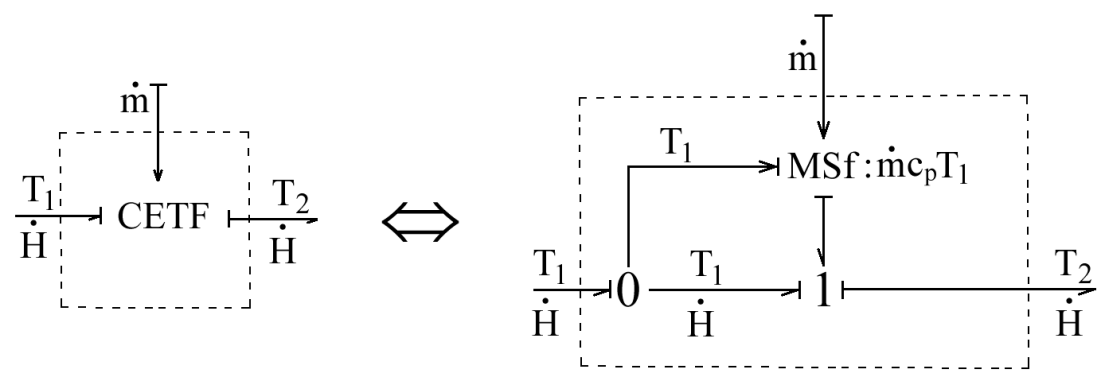

Fig.4. Expanded form of CETF element

The relationship between the efforts (temperatures $e_{1}=T_{1}$ and $e_{2}=T_{2}$ ) and flows (enthalpy flows $f_{1}=\dot{H}$ and $f_{2}=\dot{H}$ ) in the CETF element is given by

$$
\left\{\begin{array}{l}
f_{1} \\
f_{2}
\end{array}\right\}=\dot{m}\left[\begin{array}{ll}
c_{p} & 0 \\
c_{p} & 0
\end{array}\right]\left\{\begin{array}{l}
e_{1} \\
e_{2}
\end{array}\right\},
$$

where $\dot{m}$ is the mass flow rate given as a modulating signal. Note that the enthalpy flows are equal on both the power bonds and are independent of the downstream side temperature $\left(e_{2}\right)$.

The steam input is given by mass flow rate $\dot{m}_{s}$ and enthalpy flow rate $\dot{H}_{s}$, where $\dot{H}_{s}=\dot{m}_{s} h_{s}\left(P_{s}\right)$ and $h_{s}$ is a thermodynamic function, which returns the specific enthalpy of dry saturated steam entering the condenser at any given pressure. The mass and enthalpy storage in bond graph field element $\mathbf{C}_{\mathbf{s}}$ for the steam phase is given by

$$
m=\int\left(\dot{m}_{s}-\dot{m}_{c}\right) d t, \text { and } H=\int\left(\dot{H}_{s}-\dot{H}_{c}-P \dot{V}_{s}-\sum Q_{c j}\right) d t,
$$

where $P \dot{V}_{s}$ is the mechanical work due to variations in pool level. The rate of change of steam control volume is calculated as $\dot{V}_{s}=\frac{d}{d t}\left(V_{c}-V_{p}\right)=-\dot{V}_{p}$, where $V_{p}$ is the volume of condensate in the pool. Note that $V_{p}$ is a function of the differential pressure due to pool head.

The outputs from the field element $\mathbf{C}_{\mathbf{s}}$ are pressure and temperature in the steam phase, which are calculated by iteratively solving the following relation:

$$
\begin{aligned}
& v_{m}=\frac{V_{c}-V_{p}}{m}=X v_{s}\left(P_{s}\right)+(1-X) v_{l}\left(P_{l}\right), \\
& h_{m}=\frac{H}{m}=X h_{s}\left(P_{s}\right)+(1-X) h_{l}\left(P_{s}\right), \\
& T_{s}=\Phi_{P T}\left(P_{s}\right),
\end{aligned}
$$

where $V_{c}, V_{p}, v_{m}$ and $h_{m}$ are respectively internal volume of condenser, volume occupied by the stored condensate in the pool, specific volume and specific enthalpy of the steam in the condenser, and $v_{s}, v_{l}, h_{l}$ and $\Phi_{P T}$ are thermodynamic functions which return respectively the specific volume of dry saturated steam, the specific volume of saturated liquid, the 
specific enthalpy of saturated liquid, and the temperature of saturated steam, at any given pressure. From Eq.(7), the steam quality $(X)$ and steam pressure $\left(P_{s}\right)$ are solved iteratively using bisection method and the result is then used to calculate steam temperature $\left(T_{\mathrm{s}}\right)$. An alternative way of modelling storage of mixtures, which does not involve an iterative solution and uses different set of state variables, is given in [18].

The condensate storage in the pool is represented by the bond graph element $\mathbf{C}_{\mathbf{h}}$ for hydraulic energy and element $\mathbf{C}_{\mathbf{t}}$ for thermal energy. In this case, it is possible to separate the hydraulic and thermal energy storage by assuming that the condensate is incompressible and is in an under-saturated state.

Element $\mathbf{C}_{\mathbf{h}}$ produces the differential pressure head $\left(P_{l}\right)$ or pool level $(L)$, defined by the following relations:

$$
P_{l}=\Phi_{p}\left(\int\left(\dot{m}_{c}-\dot{m}_{l}\right) d t\right)
$$

where $\dot{m}_{l}$ is the rate of condensate discharge and $\Phi_{P}$ is a function, which depends on the geometry of the condenser (it is usually obtained using experimental calibration). In the simplest case, assuming a cylindrical condenser, Eq.(8) may be rewritten as

$$
P_{l}=\frac{1}{C_{h}}\left(\int\left(\dot{m}_{c}-\dot{m}_{l}\right) d t\right), \text { where } C_{h}=\frac{A_{c}}{g}
$$

The storage of thermal energy in the pool liquid is modelled using modulated bond graph element $\mathbf{C}_{\mathbf{t}}$. Its constitutive relation is given by

$$
T_{l}=\frac{\int\left(\dot{H}_{c}-\dot{H}_{l}\right) d t}{c_{p} \int\left(\dot{m}_{c}-\dot{m}_{l}\right) d t}=\frac{\int\left(\dot{H}_{c}-\dot{H}_{l}\right) d t}{c_{p} \Phi_{p}^{-1}\left(P_{l}\right)},
$$

where $\dot{H}_{l}$ is the rate of enthalpy flow with condensate discharge and $T_{l}$ is the pool temperature. Assuming a cylindrical condenser, Eq. (9) can be rewritten as

$$
T_{l}=\frac{1}{C_{t}} \int\left(\dot{H}_{c}-\dot{H}_{l}\right) d t, \text { where } C_{t}=\left(\frac{c_{p} A_{c}}{g}\right) P_{l} .
$$

The condensate discharge, represented by bond graph element $\mathbf{R}_{\mathbf{V}}$ and the enthalpy flow associated CETF element are given as

$$
\begin{aligned}
& \dot{m}_{l}=\Phi_{v}\left(C_{d}, u\right) \sqrt{P_{l}+P_{s}-P_{d}}, \\
& \dot{H}_{l}=\dot{m}_{l} c_{p} T_{l},
\end{aligned}
$$

where $u$ is the controller signal, $\Phi_{v}\left(C_{d}, u\right)$ is a function that determines the overall discharge coefficient of the valve, which depends on the constructional features of the valve and its characteristics (linear, quadratic, quick opening, equal percentage, etc.). Note that at junction $\mathbf{1}_{\mathbf{b}}$, the upstream pressure is sum of differential pool pressure and the steam pressure. The pool level controller, represented by block element LC, is defined as follows:

$$
u=\left\{\begin{array}{l}
1, \text { for } L_{p} \geq L_{\max }, \\
0, \text { for } L_{p} \leq L_{\min },
\end{array}\right.
$$

where $L_{p}=\frac{P_{l}}{\rho g}$. 
The condensation phenomena, given by Eq. (1), Eqs. (3-4) and Eq.(6), are represented by elements $\mathbf{R}_{\mathbf{n} j}$ for the $j^{\text {th }}$ section. The inputs are the steam temperature $\left(T_{s}\right)$, pool level (calculated from $P_{l}$ and used to determine $l_{s}$ from Eq. (2)) and the wall temperature $T_{w j}$. The outputs are the heat flowing from steam to condensate $\left(Q_{c i}\right)$, the mass and enthalpy flow rates of condensate $\left(\dot{m}_{c}\right.$ and $\dot{H}_{c}$ ), and the maximum fluid film thickness $\delta_{j}$, which is used in Nusselt's relation of section that is vertically below the considered section.

The heat capacity of the tube in $j^{\text {th }}$ section is represented by element $\mathbf{C}_{\mathbf{t}}$, whose value is determined as follows:

$$
C_{t j}=n_{t} c_{p m} \rho_{m} l_{j} \frac{\pi}{4}\left(D^{2}-d^{2}\right)
$$

where $l_{j}$ is the length of $j^{\text {th }}$ section. For $j=1 . . i$ and $j=(i+1) . .(2 i), l_{j}=l_{s}$. For the section submerged in the pool, i.e. $j=i, l_{j}=l-2 i l_{s}$. Likewise, the heat capacity of the coolant in $j^{\text {th }}$ section is represented by element $\mathbf{C}_{\mathbf{c} j}$ and its value is determined from

$$
C_{c j}=n_{t} c_{p} \rho l_{j} \frac{\pi}{4} d^{2} .
$$

Element $\mathbf{R}_{\mathbf{t} j \in k}$ represents longitudinal heat transfer resistance between $j^{\text {th }}$ and $k^{\text {th }}$ (consecutive) sections of the metal tube. Transverse heat transfer resistance between the metal tube and the coolant in $j^{\text {th }}$ section (depends on the coolant flow rate) is represented by element $\mathbf{R}_{\text {ctj. }}$. Convection heat transfer coefficient $h_{m l}$ is obtained experimentally. Heat transfer resistance between liquid and the metal tube submerged in the pool is represented by element $\mathbf{R}_{\mathbf{t l}}$. Heat transfer resistance between topmost segments of the tube and the un-modelled external segments exposed to the environment is modelled by element $\mathbf{R}_{\mathbf{t o}}$. The values for these elements are obtained as follows:

$$
\begin{gathered}
R_{t j_{-} k}=\frac{2\left(l_{j}+l_{k}\right)}{n_{t} \pi \lambda_{m}\left(D^{2}-d^{2}\right)}, \\
R_{c t j}=\frac{1}{n_{t} \pi d l_{s} h_{m l}}+\frac{\ln \left(\frac{D+d}{2 d}\right)}{2 n_{t} \pi \lambda_{m} l_{j}}, \\
R_{t l}=\frac{\ln \left(\frac{2 D}{D+d}\right)}{2 n_{t} \pi \lambda_{m}\left(l-2 i l_{s}\right)}, \\
R_{t o}=\frac{2 l_{s}}{n_{t} \pi \lambda_{m}\left(D^{2}-d^{2}\right)} .
\end{gathered}
$$

Junctions $\mathbf{0}_{\mathbf{Q} \text { i }}$ and $\mathbf{0}_{\mathbf{Q} \mathbf{0}}$ are used to sum the total heat transferred to the tubes from steam in the coolant inlet side and the coolant outlet side of the tube, respectively, i.e. $Q_{c i n}=\sum_{j=1}^{j=i} Q_{c j}$, and $Q_{c o}=\sum_{j=i+2}^{j=2 i+1} Q_{c j}, Q_{c}=Q_{c i n}+Q_{c o}$. Modulated sources $\mathbf{M S f}_{\mathbf{i}}$ and $\mathbf{M S f}_{\mathbf{o}}$ model the condensate mass and enthalpy flow rates (in vector form), respectively from $i^{\text {th }}$ and $(i+2)^{\text {th }}$ sections to the pool. Their relations are given by Eq. (3) and Eq.(6). Junction $\mathbf{0}_{\mathbf{c}}$ is used to sum $\mathbf{M S f}_{\mathbf{i}}$ and $\mathbf{M S f}_{\mathbf{0}}$. In steady state, the condensate flow rate is assumed to be equal to the rate of 
condensation. Thus, these mass and enthalpy flow rates represent the transfer of mass and energy from steam phase to the pool.

Note that the liquid phase is considered incompressible and all those elements whose relations involve the pool level $L$ (alternatively, volume $V_{p}$ and pressure $P_{l}$ ) are in fact modulated (e.g. $C_{t j}, R_{c t j}, C_{c j}$, for $j=1 \ldots 2 i+1$ ). These modulations are not shown in the model to maintain clarity of presentation.

The rest of the elements in the bond graph model given in Fig.3 are simple and selfexplanatory.

\section{Simulation and experimental validation}

The steam generator installation [20] at LAGIS (Laboratoire d'Automatique, Génie Informatique et Signal) was used for experimental validation of the model. The vertical condenser-heat exchanger component, shown in Fig.5, is positioned after the loading circuit (a steam expansion system mimicking a turbine) to condense the steam generated by a boiler.

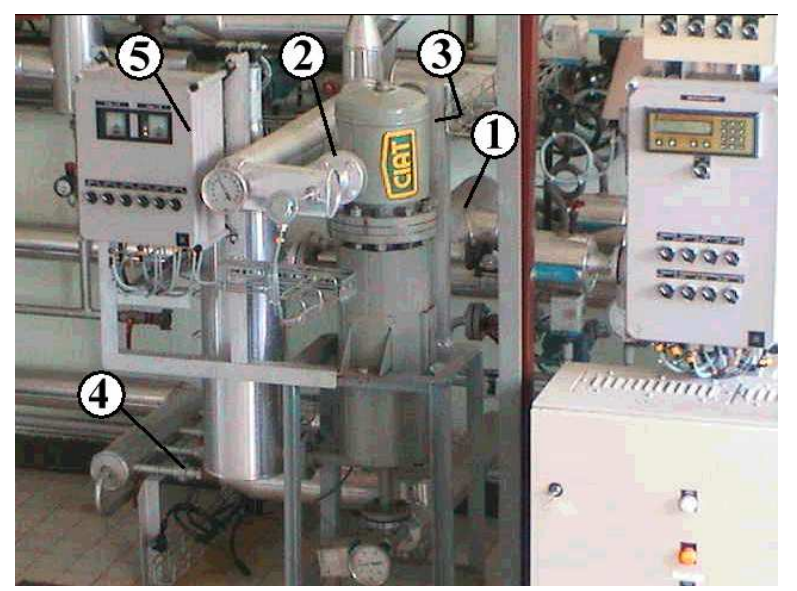

Legend:

1. Steam input

2. Coolant input

3. Coolant chamber

4. Control valve for pool discharge

5. Display panel for sensor outputs

Make: CIAT, Type: UX 16804 4P CL5

Rating: 16bars, Capacity: 8Ltrs

Fig.5. Condenser-heat exchanger component in an experimental steam generator set-up

The initial conditions for the states were calculated from steady-state process measurements. As an example, the initial conditions for states of the $\mathbf{C}_{\mathbf{s}}$-field are given as

$$
q_{s 0}=\left[\frac{\left(V_{c}-m_{p 0} / \rho\right)}{v_{s}\left(P_{s 0}\right)}, \quad h_{s}\left(P_{s 0}\right) \frac{\left(V_{c}-m_{p 0} / \rho\right)}{v_{s}\left(P_{s 0}\right)}\right]^{T},
$$

where $P_{s 0}$ is the initial steam pressure and $m_{p 0}$ is the initial mass of liquid in the pool. For the pool, initial conditions for states corresponding to elements $\mathbf{C}_{\mathbf{h}}$ and $\mathbf{C}_{\mathbf{t}}$ are given as $q_{h}=m_{p 0}$ and $q_{t 0}=m_{p 0} c_{p} T_{p 0}$, where $T_{p 0}$ is the initial temperature of liquid in the pool. Initial conditions for other state variables are calculated likewise. For each tube, the length exposed to steam, i.e. the length over which condensation takes place, is obtained from the mass (or volume) of condensate in the pool using experimental calibration as follows:

$$
\begin{aligned}
& l=l_{t}-\Phi_{c}\left(q_{h}\right)=1.56-q_{h} / 4.98, \\
& l_{s}=l / 2 i .
\end{aligned}
$$

Since it is a small condenser, we have taken $i=2$, i.e. a total of five sections. Additional data used in simulation, besides those given in Table 1, are given in Table 2. 
Table 2. Additional parameters used in simulation

\begin{tabular}{llll}
\hline Data & Description & Value & Unit \\
\hline$P_{s 0}$ & Initial steam pressure & $3.0 \times 10^{5}$ & $\mathrm{~Pa}$ \\
$m_{p 0}$ & Initial pool mass & 3.5 & $\mathrm{~kg}$ \\
$T_{p 0}$ & Initial pool temperature & 50 & ${ }^{\circ} \mathrm{C}$ \\
$T_{w 0}$ & Initial temperature of tube walls & 125 & ${ }^{\circ} \mathrm{C}$ \\
$T_{i n}$ & Inlet temperature of coolant & 44 & ${ }^{\circ} \mathrm{C}$ \\
$\alpha$ & Heat transfer correction factor & 1.15 & - \\
\hline
\end{tabular}

The value of $\alpha$ was chosen iteratively to produce best match with experimental results. It corrects the heat transfer by $15 \%$, which is in accordance with the maximum correction factor of 20\% suggested in [24]. This takes care of the uncertainties in estimating parameters such as the heat transfer coefficients, which are extremely sensitive to the surface roughness [29-30] of the inside and outside of the tubes, etc. There are some recent researches into finding good correlations for film condensation [31], but it is not easy to apply them in a physical model.

The computational model was developed using ModelBuilder [32], which is specifically designed to handle thermo-fluid system models. ASME steam tables [33] were used to obtain thermodynamic properties. The coolant flow rate and entry temperature were taken as constants as given in Tables 1 and 2, respectively; the specific enthalpy and mass flow rate of the input steam, which enters from a pressure (consequently temperature) controlled boiler after isenthalpic expansion through a valve, were taken as $2772.2 \mathrm{~kJ} / \mathrm{kg}$ and $0.004673 \mathrm{~kg} / \mathrm{s}$ (average steady-state experimental data), respectively. From the simulation, the evolution of steam pressure $\left(P_{s}\right)$, pool temperature $\left(T_{l}\right)$ and coolant temperature at exit $\left(T_{e}\right)$ are plotted in Fig. 6.

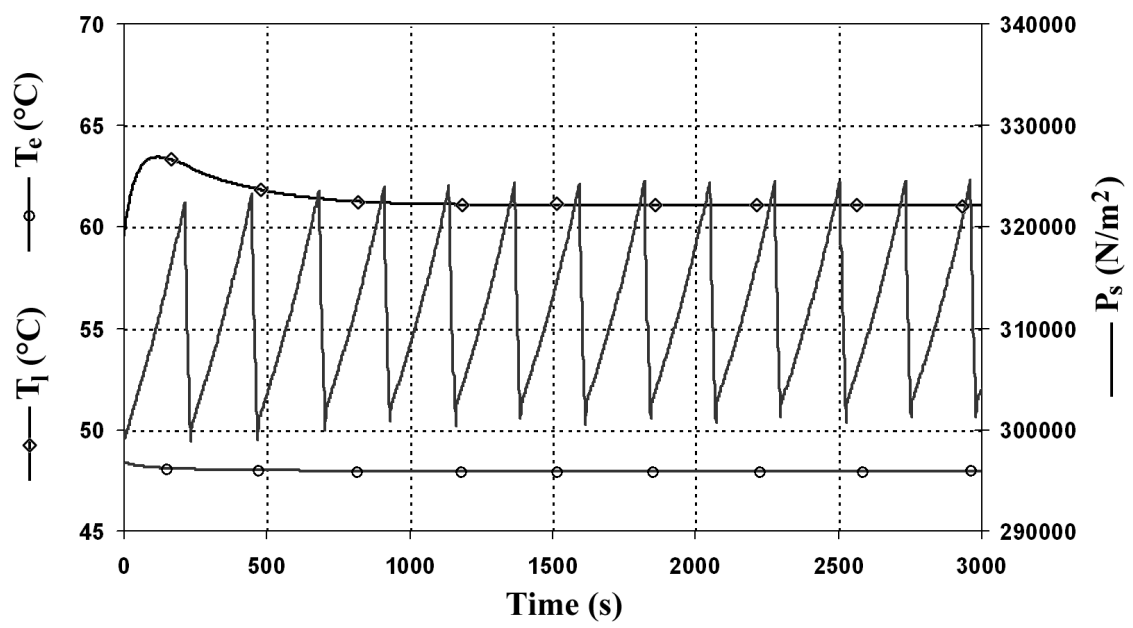

Fig. 6. Simulation results

Comparisons of the simulation results with experimental results for steam pressure and pool level are given in Fig.7(a) and Fig.7(b), respectively. These results show good agreement between the model and the real process. However, there is a phase shift between the results, which can be attributed to actuator dynamics. In the real process, the control valve used to discharge pool liquid does not immediately respond to the command given from the on-off controller. Therefore, the pool level slightly exceeds the upper threshold due to the condensation during the delay in opening the valve and it significantly falls below the lower threshold due to the extra discharge from the pool during the delay in closing the valve.

Simulation results for coolant temperature at the exit and the pool temperature are compared with their corresponding experimental results in Fig.8. The results show that the 
simulation model is able to provide good estimates of the actual values. Minor discrepancies in the values can be attributed to un-modelled heat transfers, external disturbances, and variations in the inputs (Note that we have assumed constant steam flow rate at constant specific enthalpy, constant coolant flow rate and constant coolant inlet temperature).

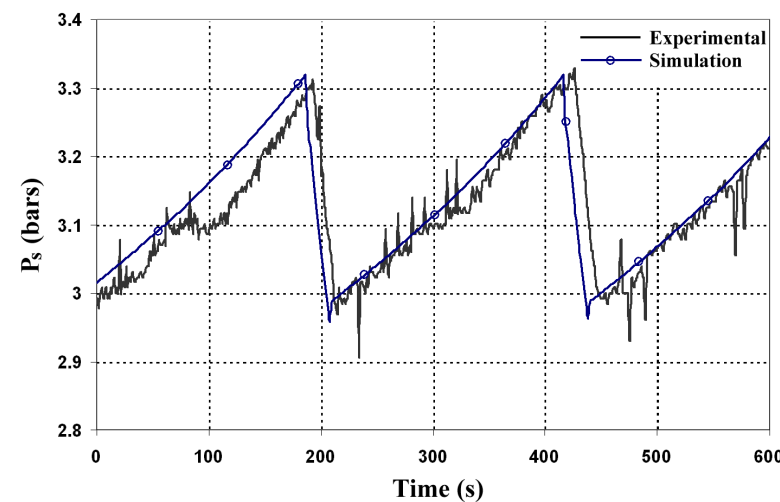

(a)

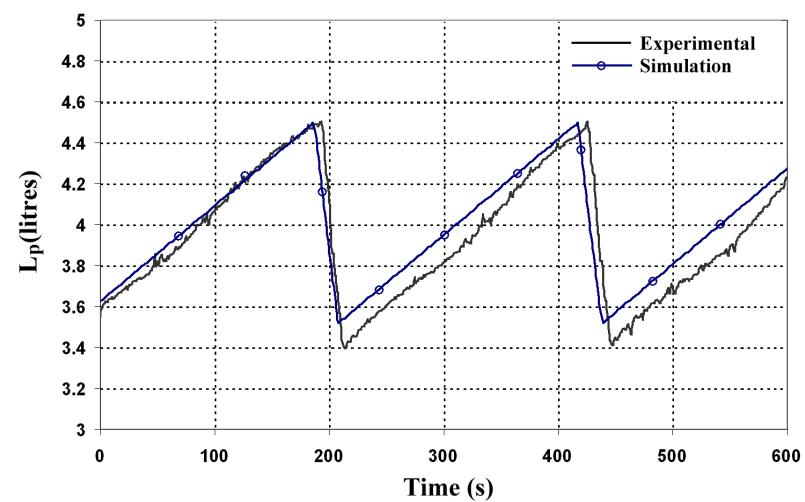

(b)

Fig. 7. Comparison of simulation and experimental results for steam pressure and pool level

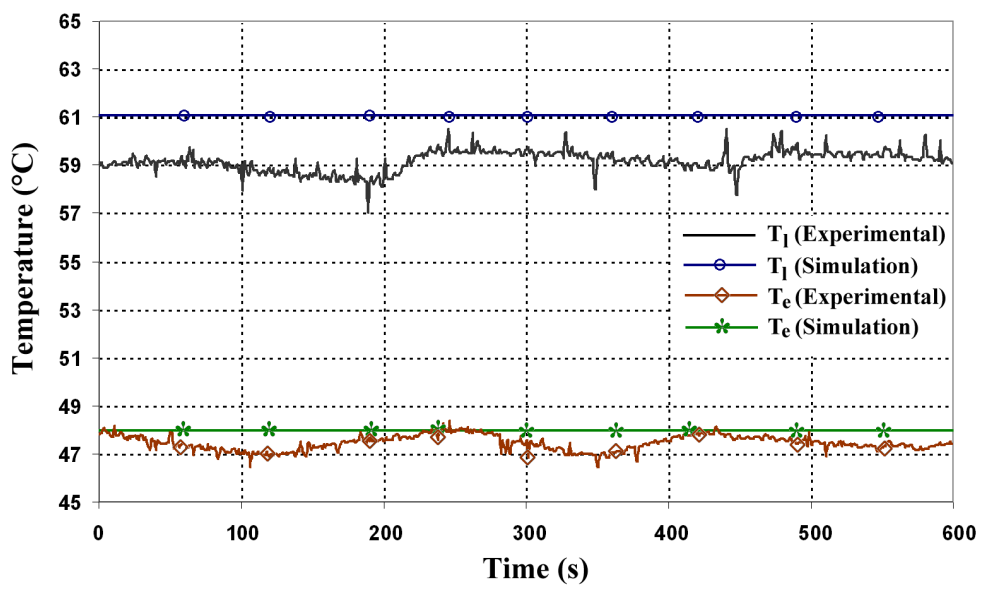

Fig. 8. Comparison of simulation and experimental results for coolant and pool temperatures

\section{Conclusions}

Pseudo-bond graph model of a vertical U-tube steam condenser is developed in this paper. The equations for elements in the model can be changed to accommodate complex heat transfer and condensation rate formulations, while the model structure remains the same. The model presented is suitable for system level dynamics studies and can serve as a template for development of more accurate solutions. Simulation results obtained from the model with an empirical correction factor of the heat transfer coefficient are then compared to the output from an experimental condenser in a steam generator installation and the results show acceptable prediction of process behaviour.

\section{References}

[1] D.C. Karnopp, D.C. Margolis, R. Rosenberg, Systems Dynamics: A Unified Approach, John Wiley, New York, 1990.

[2] J.U. Thoma, Introduction to Bond Graphs and their Application, Pergamon Press, 1975.

[3] A. Mukherjee, R. Karmakar, A.K. Samantaray, Bond Graph in Modeling, Simulation and Fault Identification, CRC Press, London, 2006. 
[4] P.C. Breedveld, Physical Systems Theory in terms of Bond Graphs, PhD Thesis, Twente University, Enschede, 1984.

[5] W. Borutzky, Bond Graphs - A Methodology for Modelling Multidisciplinary Dynamic Systems, SCS Publishing House, San Diego, 2004.

[6] M. Hubbard, J.W. Brewer, Pseudo bond graphs of circulating fluids with application to solar heating design, J. Franklin Institute 311 (6) (1981) 339-354.

[7] R. Shoureshi, K.M. McLaughlin, Analytical and experimental investigation of flow-reversible heat exchangers using temperature-entropy bond graphs, J. Dynamic Systems, Measurement and Control, 106 (2) (1984) 170-175.

[8] R. Shoureshi, K. McLaughlin, Modeling and dynamics of two-phase flow heat exchangers using temperature - entropy bond graphs, In: Proc. the American Control Conference, 1 (1984) 93-98.

[9] M. Delgado, J. Thoma, Bond graph modeling and simulation of a water cooling system for a moulding plastic plant, Systems Analysis Modelling Simulation 36 (2) (1999) 153-171.

[10] J.U. Thoma, B. Ould Bouamama, Modelling and Simulation in Thermal and Chemical Engineering: Bond Graph Approach, Springer Verlag, 2000.

[11] D. Karnopp, Pseudo bond graphs for thermal energy transport, J. Dynamic Systems, Measurements, and Control, 100 (1978) 165-169.

[12] D.C. Karnopp, State variables and pseudo-bond graphs for compressible thermo-fluid systems, J. Dynamic Systems, Measurement and Control, 101 (1979) 201-204.

[13] D.C. Karnopp, S. Azerbaijani, Pseudo bond graphs for generalised compartmental models in engineering and physiology, J. Franklin Institute, 312 (1981) 95-108.

[14] B. Ould Bouamama, Bond graph Approach as Analysis Tool in Thermo-fluid Model Library Conception, J. Franklin Institute, 340 (2003) 1-23.

[15] J.L. Tylee, Pseudo bond graph representation of PWR pressurizer dynamics, Journal of Dynamic Systems, Measurement and Control, Trans. ASME 105 (4) (1983) 255-261.

[16] A. Nebot, F.E. Cellier, F. Mugica, Simulation of heat and humidity budgets of Biosphere 2 without air conditioning, Ecological Engineering 13 (1-4) (1999) 333-356.

[17] F.T. Brown, Simulating distributed-parameter multiphase thermodynamic systems using bond graphs, ASME Dynamic Systems and Control Division (Publication) DSC 71 (2002) 545-553.

[18] F.T. Brown, Non-iterative evaluation of multiphase thermal compliances in bond graphs, Proc. Institution of Mechanical Engineers. Part I: Journal of Systems and Control Engineering 216 (1) (2002) 13-19.

[19] B. Ould Bouamama, J.U. Thoma, J.P. Cassar, Bond graph modelization of steam condensers, in: Proc. IEEE International Conference on Systems, Man and Cybernetics, 3 (1997) 2490-2494.

[20] B. Ould Bouamama, K. Medjaher, A.K. Samantaray, M. Staroswiecki, Supervision of an industrial steam generator. Part I: Bond graph modelling, Control Engineering Practice, 14(1) (2006) 71-83.

[21] L.J. Tylee, Bond graph description of U-tube steam generator dynamics, Journal of the Franklin Institute 315 (3) (1983) 165-178.

[22] W. Nusselt, Die oberflächenkondensation des wasserdampfes, VDI Zeitschrift, 60 (1916):541546 and 569-575.

[23] A.L. Chapman, Heat Transfer, Macmillan Publishing Company, 1984.

[24] W.M. Rohsenow, J.P. Hartnett, E.N. Ganic, Handbook of Heat Transfer Fundamentals, 2nd edition, McGraw-Hill Book Company, 1985.

[25] S.W. Churchill, Laminar film condensation, Int. J. Heat and Mass Transfer, 29 (1986) 12191226.

[26] V.E. Denny, A. F. Mills, Nonsimilar solutions for laminar film condensation on a vertical surface, Int. J. Heat and Mass Transfer, 12 (1969) 965-979.

[27] T.W. Botsch, K. Stephan, A model to describe the steady-state and dynamic behaviour of vertical condensers fed by mixtures, Rev Gén Therm., 36 (1997) 481-491. 
[28] N. K. Maheshwari, D. Saha, R. K. Sinha, M. Aritomi, Investigation on condensation in presence of a noncondensable gas for a wide range of Reynolds number, Nuclear Engineering and Design, 227 (2004) 219-238.

[29] S.K. Park, M.H. Kim, K.J. Yoo, Effects of a wavy interface on steam-air condensation on a vertical surface, Int. J. Multiphase Flow, 23 (1997) 1031-1042.

[30] S.K. Park, M.H. Kim, K.J. Yoo, Condensation of pure steam and steam-air mixture with surface waves of condensate film on a vertical wall, Int. J. Multiphase Flow, 22 (1996) 893-908.

[31] M. Chun, K. Kim, Assessment of the new and existing correlations for laminar and turbulent film condensations on a vertical surface, Int. Communications in Heat and Mass Transfer, 17 (1990) 431-441.

[32] B. Ould Bouamama, A.K. Samantaray, K. Medjaher, et.al., Model builder using functional and bond graph tools for FDI design, Control Engineering Practice, 13(7) (2005) 875-891.

[33] C.A. Meyer, R.B. McClintock, G.J. Silvestri, R.C. Spencer, ASME steam tables: Thermodynamic and transport properties of steam, 6th edition, ASME, 1993. 